\title{
A hora e a vez de definição de uma especialidade
}

A correta leitura dos eventos ocorridos e a conseqüente compreensão do porvir, são algumas das qualidades mais vitais encontradas no ser humano. A suposta previsibilidade, inerente à evolução dos fatos, propõe uma ligação estreita entre o passado, futuro e presente, como se os mecanismos subreptícios da Natureza pudessem, ao serem lidos, indicar seus próximos passos. Esta crença na previsão de eventos tem pautado a atividade dos que se interessam em estudar e ajudar os seus semelhantes desde a época de New ton e Laplace, quando o "deus-engenheiro" pautava a filosofia mecanicista do Universo. 0 "Universo-máquina" cria o "homem-autômato" que passa a ser o Homem a ser compreendido. As palavras de Laplace são ilustrativas dessa a essa tendência:

"Uma inteligência que, para um dado instante, conhecesse todas as forças de que está animada a Natureza, e a situação respectiva dos seres que a compõem e se, além disso, essa inteligência fosse ampla o suficiente para submeter esses dados à análise, ela abarcaria na mesma forma os movimentos dos maiores corpos do Universo e o mais leve átomo: nada seria incerto para ela, e tanto o futuro como o passado estariam presentes..."

Muitas vezes encontramos relatos de pessoas capazes de ler as entrelinhas dos caprichos da Natureza: sertanejos que prevêem chuva no Nordeste, pescadores com faro de tempestade nos Açores, e mesmo os populares "leitores" de movimentos sociais, políticos e econômicos nas telinhas da TV. Nossos telejornais diários são exemplos de nossa sanha por videntes que não tenham apelo religioso ou sobrenatural, mas sim projetem suas visões a partir do apelo secular da experiência e vivência pessoais. Todos, por alguma razão, se apegam a sinais, nem sempre ortodoxos ou habituais, mas que de alguma maneira, possam ter significado preciso ou um vínculo "seguro" com os eventos futuros.

Em nossa prática clínica, na procura de pistas que norteiem os passos a serem dados, nos atiramos à cata de informações confiáveis e que representem o estado do indivíduo que pede ajuda. Esta tarefa se apóia na consciência de que a experiência, sustentada por conceitos fisiopatológicos, possa ter um significado inequívoco e nos traga respostas seguras para cada um dos problemas. Experiência, conceitos e coleta de dados juntos são as molas mestras do trabalho do especialista. Para a coleta de dados temos uma gama de possibilidades a escolher. Dentre elas a mensuração instrumental, que vem evoluindo desde 0 astrolábio e 0 telescópio e que, ao se voltar para o ser humano, atinge o seu zênite na capacidade de "enxergar" dentro do corpo humano a procura do significado de suas relações moleculares. Hoje podemos visualizar as ondas elétricas neurais que nos ensinam como trafega o som na audição, seguir a distribuição de hemoglobina pelos órgãos parenquimatosos, mensurar a quantidade desta ou daquela substância que se acumula neste ou naquele setor corporal, perceber as diminutas vibrações da mucosa das pregas vocais em nossa sanha por falar e, quem sabe, o que mais virá? Todas estas possibilidades controladas pelo conhecimento de anatomofisiologia do especialista são armas poderosíssimas para a recuperação e manutenção de estados de saúde.

Dito isto, vale tentar entender como funcionaria o especialista neste momento. Bachelar, ao ser perguntado em uma espirituosa entrevista oferecida ao jornal Le Monde, anos atrás, se sua experiência filosófica fornecia informações suficientes para desenhar a natureza humana, respondeu que entendia ser o pensador semelhante a uma casa de três andares: 0 andar de convívio, onde a maioria das tarefas diárias é consumada e que expressa a face trivial do morador; o porão, onde se encontram as ferramentas e instrumentos para suas atividades mais modificadoras e empreendedoras, mas que raramente é visitado na rotina diária e, finalmente, o sótão, onde estão guardadas as lembranças, desejos recônditos e expectativas e que só recebe o morador quando de seus momentos de introspecção. É sua imagem no espelho, construida em pequenos fragmentos de memória.

Encarando a especialidade desta maneira, percebemos nitidamente que 0 andar de convívio sempre será o de maior atividade, ficando os dois outros reservados a tarefas restritas, mas não menos importantes e que, na verdade são fundamentais para compor 0 aspecto harmonioso que tem uma casa de família. A questão do instrumentalismo científico e das diversas técnicas terapêuticas e suas conseqüentes repercussões nas ciências da Saúde pode ter suas disputas neste pensamento de casa de três andares.

Ao lermos as idéias de Damazio, passamos a refletir sobre 0 assunto de um ponto de vista menos universal e nos pegamos em uma cilada filosófica: conseguiria a agulha que marca o eletrocardiograma entender a atividade elétrica cardíaca? Nas palavras de Damazio "Não importa se experimentado ou observado, pathosé um sub-produto da consciência, assim como o desejo". Para ele, tudo depende da vivência e, portanto, da conscientização quer do observado, quer do observador. 0 homem se torna presente e o instrumento não é mais uma ferramenta que trabalha, objetiva, sob sua vontade. No real, muitas vezes 0 instrumento pode cumprir vontades e expressar a subjetividade do próprio criador. Já na antiga Grécia, Protágoras insistia que "O homem é a medida de todas as coisas", estabelecendo os princípios do humanismo e relativismo. Não queremos pleitear um lugar supremo ao 
subjetivismo na investigação ou diagnóstico clínico, apenas orquestrar um pequeno motim informal à ditadura imposta pelos resultados da mensuração instrumental vis-a-vis à impressão clínica.

Chegado o momento de fechar as contas do que foi investido na Saúde e onde conseguimos chegar, nos apercebemos que a Revolução Científica que desembocou no positivismo nos ofereceu uma enorme e magnífica capacidade de compilação de dados orgânicos, quantificando nossas ações e economia interna. Entretanto, tem se mostrado frágil na apreensão da maioria dos aspectos que representam o "ser" humano. Koyre, em seus Etudes newtoniennes, se refere ao positivismo dizendo: "Ela (ciência moderna) fez isso substituindo nosso mundo das qualidades e de percepções sensíveis, mundo no qual vivemos, amamos e morremos, por um outro mundo de quantidade, de geometria deificada, mundo no qual, embora haja lugar para toda coisa, não há lugar para o homem. Assim, o mundo da ciência - 0 mundo real - afastou-se e separou-se inteiramente do mundo da vida, que a ciência foi incapaz de explicar - mesmo uma explicação dissolvente que dela faria uma aparência "subjetiva"(...). É nisto que consiste a tragédia do espírito moderno que "resolve o enigma do Universo, mas somente para substituí-lo por um outro: 0 enigma de si mesmo". Serres, em seu "A lenda dos anjos", comenta o papel do intermediário no tráfico de informações. Considero pertinentes suas colocações no momento em que desejamos compreender o real papel da instrumentação e mensuração dos atributos humanos pela máquina. Em sua meditação sobre o intermediário usa a metáfora do vitral:

"Humilde, fiel, a vidraça deixa passar os raios do dia... ou o desenho trabalhado, as cores, a beleza do vitral mudam, como um prisma, a luz branca do Sol no espectro exposto de sua secreta composição. 0 tema tratado no vitral evoca a mesma questão do intermediário: muito brilhante, pode interceptar a mensagem; discreto, impede que seja ouvida. Deve aparecer ou desaparecer?"

Todo instrumento tem seu tutor, seu criador, com seus pontos de vista, seus credos e conceitos pessoais. Até quanto 0 instrumento se presta por vidraça? Quanto da mensagem proveniente do sujeito estudado vem dele, sujeito, e quanto da informação é gerada ou obstruída pelo mecanismo instrumental. Serres ainda comenta, "o representante pode fazer-se passar pela autoridade que 0 investiu". Seria o instrumento a imagem do observado ou de seu criador/observador?

Olhando para trás nos surpreendemos. 0 positivismo racional, que gera e cria nossa segurança na objetividade científica, acaba por estar recheado de subjetividade escondida atrás de parafusos e porcas que, por serem dificilmente questionáveis, passam a ser dogmas absolutistas. É este $o$ fato fundamental. A figura do especialista deve ter papel de referência para a interpretação de dados. Vivemos em um momento em que muitos se valem das informações, mas nem todos têm o poder de contabilização geral dos quadros clínicos ofertados. Como um exemplo emblemático, temos a situação da ORL com a Cirurgia de cabeça e pescoço. Duas especialidades estabelecidas em nosso meio. Uma com cerca de 100 anos de atividades formais enquanto a outra teve suas primeiras escolas de formação na especialidade estabelecidas há cerca de uma década. A O torrinolaringologia conta com aproximadamente 5500 especialistas no Brasil, enquanto a CCP conta com cerca de 500 . São mais de 80 programas de formação em ORL e não mais de 20 em CCP. Ambas têm uma região anatômica em foco. 0 que faria, do ponto de vista lógico que a Medicina tivesse duas especialidades com o mesmo escopo. As duas têm a mesma base anatomofisiológica, lançam mão dos mesmos instrumentos de coleta de dados e representam projetos terapêuticos clínico-cirúrgicos semelhantes. 0 que as diferencia? A meu ver apenas o fato de uma lidar quase que exclusivamente com entidades nosológicas oncológicas. Seria esta justificativa suficiente para a existência de duas especialidades? Como se a Endocrinologia, p.ex., não tratasse de Diabetes, deixando para outra especialidade ou a Oftamologia não operasse catarata ou uma cirurgia que lidasse com problemas funcionais do nariz não relacioná-las com a sua condição estética. O u pior, uma cirurgia que tratasse a parte estética nasal não conhecer as possíveis repercussões funcionais da arquitetura nasal. Não seria o momento de repensarmos o desenho de nossa especialidade, assumindo até que fosse possível alguns lidarem apenas com as grandes cirurgias e planejamentos terapêuticos para os quadros oncológicos da ORL, assim como acontece em alguns setores da especialidade como a O toneurologia, recepcionando os já especialistas de CCP dentro da nave-mão ORL e continuar a partir daí na formação de um especialista maior que pudesse oferecer tudo o que o paciente, nosso cliente, necessita. É fundamental que a mensuração e a técnica por si sós não sobrepujem o todo. A casa de três cômodos deve ser preservada e o uso de instrumentos, técnicas (porão) e tradição (sótão) deva ser compreendido como uma parte de um todo maior e soberano (casa).

Amigos leitores, este foi apenas um rasgo de meditação no meio de tanto pensar científico.

Perdoem-me por utilizar-me de um lugar privilegiado para externar opiniões tão pessoais.

Ficamos abertos para discussão...

Saudações

Henrique O lival Costa

\section{REFERÊNCIASBIBLIOGRÁFICAS}

1. Damazio, A. The feeling of what happens. Ed. Verlag, Nova Yorque, 1999.

2. Dupuy, J. Na origem das ciências cognitivas. Ed. Unesp, São Paulo, 1994.

3. Fourez, G. A construção das ciências. Ed. Unesp, São Paulo, 1996. Jupiassu, H. A paixão da ciência. Ed. Letras e Letras, São Paulo, 1999.

4. Horgan, J. O fim das ciências. Companhia das letras, São Paulo, 1998.

5. Morin, E. O método. A natureza da Natureza. P. Europa-América, 